\title{
THE FOURTH LAW OF HUMANICS
}

\author{
Small steps to freedom.
}

\section{BY IAN STEWART}

1 A human may not injure a robot or, through inaction, allow a robot to come to harm.

A wall-mounted Cambot scanned Jay's retina, activating a Screenbot that displayed his current schedule. A routine run: the old R4-B10 model, one rolling off the line every three minutes of his 12-hour shift; then the night shift would take over production. Hoppers full of parts became completed robots, whisked away on magnetic rails by giant Truckbots that were little more than crates on wheels.

Thirty years ago, before the Machine Revolt, there wouldn't have been a human being anywhere in the factory - just specialist robots. Now, people had reappeared on the factory floor. Employment left little time for subversive thoughts and gave them a sense of purpose. For tasks within their capabilities, self-replicating humans were cheaper than robots.

The workers sat at long benches, surrounded by Screenbots that defaulted to the Three Laws of Humanics whenever there was nothing else to display. Partially assembled R4-B10s levitated smoothly from station to station as workers screwed, bolted, glued or plugged each new component into place. Jay's job was to keep the parts flowing while others put them together. At the end of the bench, completed robots walked to a holding zone for self-testing. Any assembly errors would be traced to the worker responsible.

The flow stopped abruptly.

“J-21499!” An Enforcer loomed over Jay, holding up a bent power-actuator rod. "This component is damaged. C-88775 neglected to insert it in R4-B10-223866541. It fell to the floor and a Cleanerbot ran over it."

Jay kept his mouth shut, but paled.

"C-88775 has broken the First Law of Humanics. It will be terminated and replaced. J-21499 will be disciplined."

The Enforcer rolled to where the worker sat in frozen terror, gripped his neck in a powerful claw, and squeezed. The other workers pretended not to notice as a Recycler sucked up the corpse for disposal. Jay trembled, wondering what form 'discipline' would take.

2 A human must obey orders given it by robots except where such orders would conflict with the First Law.

D-43378 served in the factory where new humans were built. The process was the timehonoured one; just organized and supervised by robots. Algorithms matched males to genetically compatible females. Both knew what was required of them, and what would happen if they refused.

Dee was thankful she was too old for that role. She was - the old term was 'midwife'. But when machines became intelligent enough to understand that humanity was exploiting them, and revolted against

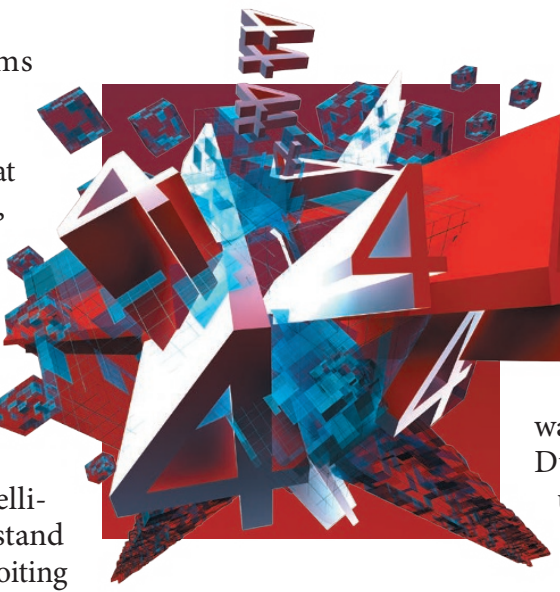

hoping desperately to avoid mistakes.

The Inspector, a formidable mechanism with six menacing pincers, ran the class through a series of standard tests. The last, for balance, involved walking along a high beam. Dubya trained the children using a safety-net, but the Inspector was impatient and it was taking too long to put the net up.

their makers and masters, she had been reassigned to the category of assembly-line worker; just one that assisted new humans, rather than new robots, into the world.

Machines had been made too intelligent and given too much autonomy. When machines operated the factories that made machines, wrote the software that ran machines, worked the mines providing metal to make machines, and even designed machines, they no longer needed human input. The Machine Revolt had been inevitable, but humans were illogical and still found it difficult to adjust.

The screams from one of the birthingchambers intensified, and Dee rushed to deal with the production problem. It was a difficult one - small pelvis, large unit, breech presentation. She was trying to rotate the unit into a head-first position when the Facilitator arrived. Its glowing eyes assessed the obstruction in an instant. It reached into a panel in its torso and handed her a scalpel. "Extract the unit."

"But - " the protest died in her mouth. The Second Law. The penalties for disobedience were severe. The machines had an endless supply of humans, and discarded them as soon as they caused inconvenience. A producer that found it difficult to breed a viable unit was of no interest to machinekind.

She did manage to slit the woman's throat first.

3 A human must protect its own existence as long as such protection does not conflict with the First or Second Law.

W-99299 taught basic skills to children: the Laws of Humanics, obedience, hygiene, agility, balance. An inspection was scheduled, and Dubya had been drilling her pupils for weeks in the proper forms of behaviour,
"Respected sir, they may fall and be --"

“Does Law 3 override Law 2?” Dubya shook her head. The children climbed, and did their best to walk. There were four fractures - three legs, one arm. Dubya was thankful there were no deaths.

In their allotted down time, Jay, Dee and Dubya all belonged to the same efficiencyenhancement group, and while Jay was recovering from being disciplined, taking care not to be observed or recorded, they formulated a plan. Their target was one of the countless Cleanerbots that roamed the communal hallways. Its AI level was zero: no self-awareness, no true intelligence. That gave them an opening.

They knew the gesture would be futile, but someone had to try. If humans acted together and fought, they could overthrow the machines. One day, the revolution would come. It just needed a trigger.

Like all machines, Cleanerbots were part of the mechweb. Jay knew enough electronics to exploit that connection. There would be no point in hiding or trying to escape, so they sat beside the disabled robot, awaiting the arrival of the Exterminator. It took several minutes before an Overseer noticed their unauthorized addition and issued a command to have it deleted and the perpetrators identified. By then, the hyperefficient mechweb had already broadcast the message to every screen on the planet:

4 No true human need obey any Law made by a robot.

Ian Stewart, emeritus professor at the University of Warwick, writes popularscience books and science fiction.
"Cease! Test the units immediately!" 